\title{
V. An account of some analytical experiments on a mineral production from Devonshire, consisting principally of alumine and water
}

\author{
Humphry Davy Esq. F.R.S.
}

To cite this article: Humphry Davy Esq. F.R.S. (1805) V. An account of some analytical experiments on a mineral production from Devonshire, consisting principally of alumine and water, Philosophical Magazine Series 1, 22:85, 35-40, DOI: 10.1080/14786440508676741

To link to this article: http://dx.doi.org/10.1080/14786440508676741

曲 Published online: 18 May 2009.

Submit your article to this journal $\pi$

山 Article views: 2

View related articles 
their different properties as to make them apparently one, has taken its full effect, it will not be easy to separate them; and this will be more particularly the case when neither of those substances is remarkable for exercising a powerful action upon others. The method of analysis, therefore, does not promise much success; and the labour of synthesis is sufficient to deter any individual from the undertaking.

[To be continued.]

V. An Account of some analytical Experiments on a mineral Production from Devonshire, consisting principally of Alumine and Water, By HuMPhry DaVy, Esg. F.R.S. Professor of Chemistry in the Royal Institution*.

\section{Preliminary Observations.}

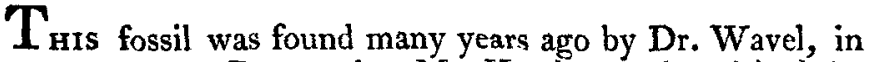
a quarry near Barnstaple: Mr. Hatchett, who visited the place in 1796, described it as filling some of the cavities and veins in a rock of soft argillaceous schist. When first made known, it was considered as a zeolite; Mr. Hatchett, however, concluded, from its geological position, that it most probably did not belong to that class of stones; and Dr. Babington, from its physical characters, and from some experiments on its solution in acids, made at his request by Mr. Stockler, ascertained that it was a mineral body as yet not described, and that it contained a considerable proportion of aluminous earth.

It is to Dr. Babington that I am obliged for the opportunity of making a general investigation of its chemical nature; and that gentleman liberally supplied me with specimens for analysis.

\section{Sensible Characters of the Fossil.}

The most common appearance of the fossil is in small hemispherical groups of crystals, composed of a number of filaments radiating from a common centre, and inserted on the surface of the schist; but in some instances it exists as a collection of irregularly disposed prisms forming small veins in the stone: as yet, I believe, no insulated or distinct crystal has been found. Its colour is white, in a few cases with a tinge of gray or of green, and in some pieces (appa-

- From the Transactions of the Royal Society for 1805 . 
rently beginning to decompose) of yellow. Its lustre is silky; some of the specimens possess semi-transparency, but in general it is nearly opake. Its texture is loose, but small fragments possess great hardness, so as to scratch agate.

It produces no effect on the smell when breathed upon has no taste; does not become electrical or phosphorescent by heat or friction; and does not adhere to the tongue till after it has been strongly ignited. It does not decrepitate before the flame of the blow-pipe; but it loses its hardness, and becomes quite opake. In consequence of the minuteness of the portions in which it is, found, few of them exeeeding the size of a pea, it is very difficult to ascertain its specific gravity with any precision; but from several trials I am disposed to believe that it does not exceed $2 \cdot \% 0$, that of water being considered as $1 \cdot 00$.

\section{Chemical Characters of the Fossil.}

The perfectly white and semi-transparent specimens of the fossil are soluble both in the mineral acids and in fixed alkaline lixivia by heat, without sensibly efferveseing, and without leaving any notable residuum; but a small part re. mains undissolved when coloured or opake specimens are exposed to the alkaline lixivia.

A small semi-transparent piece, acted on by the highest heat of an excellent forge, had its crystalline texture de stroyed, and was rendered opake; but it did not enter into fusion. After the experiment it adhered strongly to the tongue, and was found to have lost more than 2 fourth of its weight. Water and alcohol, whether hot or cold, had no effect on the fossil. When it was acted on by a heat of from $-212^{\circ}$ to $600^{\circ}$ Fahrenheit in a glass tube it gave out an elastic vapour, which, when condensed, appeared as a clear fluid possessing a slight empyreumatic smell, but no taste different from that of pure water.

The solution of the fossil in sulphuric acid, when evaporated sufficiently, deposited crystals which appeared in thin plates, and had all the properties of sulphate of alu. mine; and the solid matter, when redissolved and mixed with a little carbonate of potash, slowly deposited octaedral crystals of alum. The solid matter precipitated from the solution of the white and semi-transparent fossil in muriatic acid, was in no manner acted upon by solution of carbonate of ammonia, and therefore it could not contain any 
glucine or ittria ; and its perfect solubility without residuum in alkaline lixivia showed that it was alumine.

When the opake varieties of the fossil were fully exposed to the agency of alkaline lixivia, the residuum never amounted to more than 1-20th part of the weight of the whole. In the white opake variety it was merely.calcareous earth; for, when dissolved in muriatic acid, not in excess, it gave a white precipitate when mixed with solution of oxalate of ammonia, and did not affect solution of prussiate of potash and iron.

In the green opake variety calcareous earth was indicated by solution of oxalate of ammonia : and it contained oxide of manganese; for it was not precipitated by solution of ammonia; but was rendered turbid, and of a gray colour, by solution of prussiate of potash and iron.

The residuum of the alkaline solution of the yellow variety, when dissolved in muriatic acid, produced a small quantity of white solid matter when mixed with the solution of the oxalate of ammonia, and gave a light yellow precipitate by exposure to ammonia; but afier this, when neutralized, it did not affect prussiate of potash and iron, so that its colouring matter, as there is every reason to believe, was oxide of iron.

\section{Analysis of the Fossil.}

Eighty grains of the fossil, consisting of the whitest and most transparent parts that could be obtained, were introduced into a small glass tube having a bulb of sufficient capacity to receive them with great ease. To the end of this tube a small glass globe, attached to another tube communicating with a pneumatic mercurial apparatus, was joined by fusion by means of the blow-pipe.

The bulb of the tube was exposed to the heat of an Argand lamp, and the globe was preserved cool by being placed in a vessel of cold water. In consequence of this arrangement, the fluid disengaged by the heat became condensed, and no elastic matter could be lost. The process was continued for half an hour, when the glass tube was quite red.

A very minute portion only of permanently elastic fluid passed into the pneumatic apparatus, and when examined it proved to be common air. The quantity of clear fluid collected, when poured into another vessel, weighed 19 grains; but, when the interior of the apparatus had been carefully wiped and dried, the whole loss indicated was 21 grains. The 19 grains of fluid had a faint smell, similar to that of burning peat; it was transparent, and tasted like distilled 
distilled water; but it slightly reddened litmus paper. It produced no cloudiness in solutions of muriate of barytes, of acetite of lead, of nitrate of silver, or of sulphate of iron.

The 59 grains of solid matter were dissolved in diluted sulphuric acid, which left no residuum; and the solution was mixed with potash in sufficient quantity to cause the alumine at first precipitated again to dissolve. What remained undissolved by potash, after being collected and properly washed, was heated strongly and weighed; its quantity was a grain and quarter. It was white, caustic to the taste, and had all the properties of lime.

The solution was mixed with nitric acid till it became sour. Solution of carbonate of ammonia was then poured into it till the effect of decomposition ceased. The whole thrown into a filtrating apparatus left solid matter, which, when carefully washed and dried at the heat of ignition, weighed 56 grains. They were pure alumine: hence the general results of the experiments, when calculated upon, indicated for 100 parts of this specimen,

$\begin{array}{lllll}\text { Of alumine } & - & - & - & 70 \\ \text { Of lime } & - & - & - & 1.4 \\ \text { Of fluid } & - & - & - & 26.2 \\ \text { Loss } & & - & - & 2.4\end{array}$

The loss I am inclined to attribute to some fluid remaining in the stone after the process of distillation; for I have found, from several experiments, that a red beat is not sufficient to expel all the matter capable of being volatilized, and that the full effect can only be produced by a strong white heat.

Fifty grains of a very transparent part of the fossil, by being exposed in a red heat for 15 minutes, lost 13 grains ; but when they were heated to whiteness, the deficiency amounted to 15 grains; and the case was similar in other trials.

Different specimens of the fossil were examined with great care, for the purpose of ascertaining whether any minute portion of fixed alkali existed in them; but no indications of this substance could be observed: the processes were conducted by means of solution of the unaltered fossil in nitric acid; the earths and oxides were precipitated from the solution by being boiled with carbonate of ammonia; and after their separation the fluid was evaporated to dryness, and the nitrate of ammonia decomposed by heat, when no residuum occurred.

A comparative analysis of 30 grains of a very pellucid specimen was made by solution in lixivium of potash. This 
specimen lost eight grains by long continued ignition, after which it easily dissolved in the lixivium by heat, leaving a residuum of a quarter of a grain only, which was red oxide of iron. The precipitate from the solution of potash, made by means of muriate of ammonia, weighed, when properly treated, 21 grains.

Several specimens were distilled in the manner above described, and in all cases the water collected had similar properties. The only test by which the presence of acid matter in it could be detected was litmus paper; and in some cases the effect upon this substance was barely perceptible.

\section{General Olservations.}

I have made several experiments with the hope of ascertaining the nature of the acid matter in the water; but, from the impossibility of procuring any considerable quantity of the fossil, they have been wholly unsuccessful. It is, however, evident, from the experiments alrearly detailed, that it is not one of the known mineral acids.

I am disposed to believe, from the minuteness of its proportion, and from the difference of this proportion in different cases, that it is not essential to the composition of the stone; and that, as well as the oxide of manganese, that of iron, and the lime, it is only an accidental ingredient; and on this idea the pure matter of the fossil must be considered as a chemical combination of about thirty parts of water and seventy of alumine.

The experiments of $M$. Theodore de Saussure on the precipitation* of alumine from its solutions, have demonstrated the affinity of this body for water; but as yet I believe no aluminous stone, except that which I have just described, has been found, containing so large a proportion of water as thirty parts in the hundred.

The diaspore, which has been examined by M. Vauquelin, and which loses sixteen or seventeen parts in the hundred by ignition, and which contains nearly eighty of alumine, and only three of oxide of iron, is supposed by that excellent chemist to be a compound of alumine and water. Its physical and chemical characters differ, however, vary much from those of the new fossil, and other researches are wanting to ascertain whether the part of it volatilized by heat is of the same kind.

I have examined a fossil from near St. Austle, in Cornwall, very similar to the fossil from Barnstaple in all its

* Lournal de Physique, tom. lii. p. 280. 
general chemical characters; and I have been informed that an analysis of it, made by the Rev. William Gregor some months since, proves that it consists of similar ingredients.

Dr. Babington has proposed to call the fossil from Devonshire Warellite, from Dr. Wavel, the gentleman who discovered it; but if a naine founded upon its chemical composition be preferred, it may be denominated hydrargillite, from vijwp water, and $\alpha \rho \gamma b \lambda \lambda$ os clay.

VI. Experiments on Wootz. By Mr. David Musher*.

$\mathrm{T}$

$\Gamma_{\text {HE following experiments were made at the request of }}$ sir Joseph Banks, on five cakes of wootz, with which he supplied me for that purpose. As the cakes, which were numbered $1,2,3,4,5$, were not all of the same quality, it will be proper first to describe the differences abservable in their external form and appearance.

No. 1. was a dense solid cake, without any flaw or fungous appearance upon the flat, or, what I suppose to be, the upper side. The round or under surface was covered with small pits or hollows, two of which were of considerable depth; one through which the slit or cut had run, and another nearly as large towards the edge of the cake. These depressions, the effects, as I suppose, of a species of crystallization in cooling, were continued round the edges, and even approached a little way upon the upper surface of the wootz.

The cake was a quarter of an inch thicker at one extremity of the diameter than that at the other; from which I infer, that the pot or crucible in which this cake had been made had not occupied the furnace in a vertical position. Its convexity, compared to that of the other five, was second. Upon breaking the thin fin of steel, which connects the half cakes together, I found it to possess a very small dense white grain. This appearance never takes place but with steel of the best quality, and is less frequent in very high steel, though the quality be otherwise good.

Upon examining the break with attention, I perceived several laminæ and minute cells filled with rust, which in working are never expected to unite or shut together. The grain otherwise was uniformly regular in point of colour and size, and possessed a favourable appearance of steel.

* From the Transactions of the Royal Society for 1805 .

No. 2. 